\title{
ON THE PHILOSOPHICAL METHOD: THERAPY?
}

\author{
[SOBRE O MÉTODO FILOSÓFICO: TERAPIA?]
}

\author{
Nara M. Figueiredo * \\ UIversidade Estadual de Campinas, UNICAMP, Brasil
}

\begin{abstract}
This paper presents a critique of Baker's interpretation of Wittgenstein's method. First, there is a brief presentation of his view according to which the philosophical method is a therapy of the subject. This is followed by the arguments against his main assumptions and finally by an exegetical analysis of Wittgenstein's uses of 'psychoanalysis'. The general aim is to explain why Baker's view is not convincing.
\end{abstract}

KEYwORDs: method, therapy, subject, affliction.
RESUMo: Este artigo apresenta uma crítica à interpretação de Baker do método de Wittgenstein. Primeiramente, há uma breve apresentação de sua visão, segundo a qual o método filosófico é uma terapia do sujeito. Isso é seguido pelos argumentos contra suas principais suposições e, finalmente, por uma análise exegética dos usos de Wittgenstein do termo "psicanálise". O objetivo geral é explicar porque a proposta de Baker não é convincente.

Palavras-chave: método, terapia, sujeito, aflição.

\section{1- INTRODUCTION: "OUR METHOD"}

This essay aims to point out some problematic features of Baker's view on the role of philosophy and discuss the validity of grounding on Wittgenstein what Baker conceives as "our method'. Despite mentioning that his purpose is not to state what philosophy is, but to offer the philosophical therapeutic method as an option - "it is 'our method' (not philosophy in general) which is said to have some resemblance with psychoanalysis." (BAKER, 2004, 207), - saying that this view is in Wittgenstein is excessive. I shall point out some reasons for this statement. For this, I will give a short overview of what is involved in Baker's considerations and then I'll discuss a few points based on the distinction between concepts and feelings. After that, I present an exegetical approach, mentioning most occurrences of the word 'psychoanalysis' in Wittgenstein's work, in order to emphasize that his approach does not give room to a close association between philosophy and psychoanalysis as Baker defends.

\section{1 - Baker's view}

First of all, we have to consider that Baker is taking Waismann's (1968) writings as Wittgenstein's view based merely on these two facts: (1) they apparently shared the

* Post-doctoral researcher at the State University of Campinas. E-mail: naramfigueiredo@gmail.com 
same conception during the time in which Wittgenstein dictated to Waismann (see WITTGENSTEIN, WAISMANN; BAKER, 2003) and (2) Waismann's writings are based on those dictations. "The vision of philosophy that Waismann elaborated in 1956 seems to have been Wittgenstein's own at least in the early 1930s." (BAKER, 2004, 179), says Baker. And, according to him, Waismann's writings seem to have the key to unlock the method whereby Wittgenstein conducted his philosophical investigations, because they aim to exhibit the method learnt from Wittgenstein.

In his considerations Baker states that he uses Waismann's model as an object of comparison to understand what he defends as Wittgenstein's method, but later his aim is to clarify/dissolve a supposed contra-sense in Waismann's view and validate his method as Wittgenstein's method for at least a period, as he says. "Waismann outlined not an analogy, but a revolutionary programme. It is a description of a very distinctive method which appears to have dominated Wittgenstein's work at this period." (BAKER, 2004, 179, see also BAKER, 2003) ${ }^{2}$.

The four pillars of Waismann's conception considered by Baker in order to highlight supposedly neglected aspects of the Philosophical Investigations are: First, the distinction between philosophical questions and everyday questions in the sense that philosophical questions don't require information and, in general, obvious answers are already known by the questioner himself (BAKER, 2004, 146). Although they have an obvious answer the subject who raises them is involved in a kind of puzzlement. This is the second point. The puzzlement is due to the subject's preconceptions and prejudices, that determine his way of seeing, and it should be dissolved by a careful description of the use of the words in the formulation of the questions. Thirdly, philosophical discussion aims to clarify grammar in order to cultivate self-awareness, in the sense that the subject should understand his own rules, especially the ones that guided his thinking on philosophical questions. So, clarifying grammar is essentially relative to the subject and should be especially determined by his way of speaking. Finally, the fourth point is what this philosophical enterprise involves. It involves a high degree of imagination and sensitivity of the philosopher in order for him to provide appropriate analogies that can persuade the subject. The subject has to accept a new way of seeing spontaneously. And in this sense the essence of this method lies in liberty. ${ }^{3}$

Furthermore, Waismann's therapeutic method is characterized by Baker as follows: Waismann associates philosophical problems with states of mind such as, torment, angst, craving, prejudice, superstition, illusion and so on. In this sense, solving a philosophical problem is bringing relief to a person who is suffering or unhappy. Obsessions and prejudices are powered by the modals: "What appear to be necessary truths generate intolerable conflicts within the patient: 'This is not how it is - but this is how it must be!"' (BAKER, 2004, 152)

According to Baker, what constitutes the analogy between psychoanalysis and the method are five features that, as he holds, are common between them. First, as psychoanalysis, the philosophical method is directed exclusively to the subject. The therapeutic philosopher, like the psychoanalyst, engages with someone who is suffering from some illness, once philosophical problems are associated with personal states of torment. There is nothing of concern to the philosopher if there is nobody suffering due to philosophical problems. In other words, there are no problems by themselves. Second, like psychoanalysis, the purpose of the philosophical method is to treat internal conflicts. The difference between them on this aspect is that psychoanalysis treats compulsions, obsessions and neuroses whereas the philosophical method aims to show the subject how his conflicts are based on his way of seeing. Third, both psychoanalysis and philosophical therapy admit only rational dialogue as treatment. Even if the 
arguments are not being logically concatenated, it doesn't mean that the discussion lacks rationality. Fourth, achieving an understanding of oneself is the common aim, and the process of reaching it has two components: bringing unconscious things to consciousness, and tracing the roots that lead to the misleading conceptions. [Baker 2004, 153] And fifth, the acknowledgement. The subject's acknowledgement of the mistake and the acceptance of the therapy in order for him to leave his old way of thinking is required. This occurs because, in looking in a different way the subject accepts, spontaneously, a new way of seeing.

Based basically on the above mentioned features, Baker defends the view that "Waismann outlined not an analogy, but a revolutionary programme. It is a description of a very distinctive method (...)" (Baker 2004, 179). Method by which, according to him, freedom and spontaneous decision are increased when submitted to clarifying grammar. This is because the misleading prejudices, false analogies and ways of seeing that shape our thinking and lead us to the philosophical problems, or what he calls philosophical torments, deprive us of our freedom in thinking since they are unconscious/hidden staples restricting what we must think (BAKER, 2004, 185).

\section{2 - WHY THE ANALOGY BETWEEN PSYCHOANALYSIS AND PHILOSOPHY CANNOT BE CONCEIVED IN BAKER'S TERMS.}

My considerations about Baker's view regard (1) the difference between prejudices and states of mind, (2) the 'location' of problems and (3) the supposed difference between objects and causes. Furthermore, as mentioned above, we shall note Wittgenstein's references below and the role of the analogy between philosophy and psychoanalysis.

The difference between conceptions and states of mind is an important distinction that is underestimated by Baker and that can affect his whole conception. Let's consider this statement: “(...) troubled or unhealthy states of mind: 'torment', 'Angst', 'disquiet', 'craving', 'prejudice', 'superstition', 'illusion', etc.” (Baker 2004, 151). Are these all states of mind? Well, when we talk about states of mind or when we say someone is in a state of mind, we usually use words like 'tormented', 'agonized', 'disquieted', 'anxious', 'contented' etc. and these words are always more or less related to moods and feelings. Or we even use 'delusional', 'appreciative', 'introspective', 'focused', 'distracted' 'creative' etc. which are less related to feelings but are related to 'driving attention to'.

On the other hand, when we talk about 'prejudices' and 'superstitions' we are talking about judgments, opinions, beliefs or notions that, generally speaking, are not based on reasoning or knowledge, as opposed to judgements and beliefs. This indicates that the concepts of prejudice and superstition are related to concepts like opinion, belief, conception, reasoning, knowledge to the extent that they are all somehow related to what we can state in contrast to what we can feel (roughly speaking) - although we can also state what we feel, we cannot feel what is stated, unless we refer to feeling something about what is stated, but this is a different case. Is prejudice a state of mind? Are we not supposed to differentiate mood/feelings from conceptions? This distinction is evident when we consider that we don't 'feel' a prejudice. We 'have' a prejudice, as we 'have' a superstition, as we 'have' an opinion, a belief, a conception etc. in contrast with 'we feel anxious or tormented'.

The mere fact of noticing this difference (the difference between prejudices and states of mind) unsettles Baker's whole conception of philosophical treatment because it 
shakes one of his first pillars, namely the association of philosophical problems with states of mind. Prejudice can bring a philosophical problem, but it is definitely not a state of mind in the same sense that we would say that feeling tormented is. Thus, prejudice is not, by itself, a philosophical problem, but it can bring philosophical problems (among other things) and it may need to be broken/dissolved by philosophy. This distinction is of the same nature as this one: We don't 'suffer' from a problem. We can have a problem that makes us suffer.

Regarding the 'location' of problems I should defend that considering that there are no problems by themselves is at least a weak consideration. As we saw, Baker considers that "In the absence of a particular person with a particular complaint, there is literally nothing constructive for a philosopher to do." (BAKER 2004, 152). In other words, we cannot treat a suffering/affliction which is not someone's suffering. This implies that there is no suffering by itself, but just the suffering subject. There is no problem with this formulation if we are talking about suffering, because it is perfectly fine to say that there is no suffering by itself; but if we consider, as he does ${ }^{4}$ that the philosophical problem is the suffering, we are led to think that there are no philosophical problems by themselves. I have two objections to this idea. The first one is: if he acknowledges that the suffering patient can be an imaginary interlocutor, this whole idea of a suffering being essentially related to a subject falls apart, precisely because if it is an imaginary interlocutor, it is not a suffering subject. Naturally, one could say that there are subtleties in Baker's arguments that allow this exception, such as, in case we consider that the imaginary interlocutor is something like a temporary subject to a suffering that was, is or will be related to an actual subject. Nevertheless, I want to point out that if the patient is an imaginary interlocutor the suffering would be not only arbitrary but also subjected to one's own imagination, which makes it difficult for us to seriously conceive a problem, since the suffering is contingent. In other words, if we consider that we could have an imaginary interlocutor, wouldn't it mean the same as saying that there is a problem? - in a particular formulation of words? If I can attribute the problem to an imaginary interlocutor, it means that there is nobody suffering from an affliction, but there is a problem to be handled - even if it is a problem of an imaginary interlocutor that is not necessarily suffering. The question is: What supports a necessary relation between a problem and a sufferer? We could say that it is the same that supports a necessary relation between language and subjects/speakers, but if we want to say that the problem is somewhere, we should say that the problem is in language 5 and it concerns us to the extent that we are language users. Of course a problem in language can generate afflictions in someone, but that's another thing. It doesn't mean philosophy should treat afflictions. Philosophy can dissolve problems in language that eventually can relieve someone's afflictions, but this is totally contingent.

My second observation is related to the previous point: once we get the distinction between suffering and having a philosophical problem we realize that unlike suffering - that is directly related to a subject - the philosophical problem involves the subject only to the extent that he is a language user. And, as a consequence of that, it is mistaken to say that the method in PI is a therapeutic method that regards essentially the subject, since it regards the subject only to the extent that it is a language user. I raise this second point because, to Baker, the private language argument (PLA) [BAKER 2004,152 ] can be considered as an example of an imaginary interlocutor; but, as I said, if we agree that there can be no therapy of an imaginary interlocutor because there is nobody suffering from a philosophical problem, and we agree that the PLA is an example of Wittgenstein's method, we have to say that Wittgenstein's method in PI is not the therapeutic method as understood by Baker. 
For the difference between objects and causes [BAKER 2004, 183], I should say, in the same line of thought of my previous comment, that it is lacking the realization that the problem causes the suffering. To Baker, the distinction between the supposed philosophical suffering and another kind of suffering, like headaches, is drawn by the fact that philosophical suffering has a particular kind of object associated, unlike headaches that have only causes. But, as we saw before, if the philosophical problem is not the affliction itself, but can only generate an affliction, isn't this the same, or at least analogous, as saying, in this context ${ }^{6}$, that the object of the suffering (paradoxes, contradictions, entanglements in our own rules - philosophical problems) causes the suffering?

My main concern, that is common among the three points I have raised, is the distinction between the conceptual level and the sentimental/emotional level. Although I am not providing a detailed account for what it means to say that something is a feeling or that something is a concept, we must acknowledge that the mere categorical distinction between a concept (or conception) and what it produces in us, namely, feelings/anxiety, is sufficient for us to see that we cannot take them as the same thing. And this distinction is clearly considered in PI: "A simile that has been absorbed into the forms of our language produces a false appearance which disquiets us." (WITTGENSTEIN 2009, §112). So that, when Wittgenstein says 'our language' he is talking about our concepts. A philosophical problem is an entanglement in our ways of speaking, in our concepts. It is a false appearance that disquiet us.

In conclusion, the analogy between psychoanalysis and the philosophical method should not be taken so deeply, but as a means to highlight similarities and differences; a way to point at the direction we should look. One of the points that the analogy highlights is how important it is that the interlocutor is willing to consider things in a different way. Let us now look at the analogies more closely.

\section{3 - THE EXEGETICAL APPROACH: THE REFERENCES TO 'PSYCHOANALYSIS'.}

Regarding Wittgenstein's references of 'psychoanalysis', it is remarkable that Wittgenstein doesn't mention psychoanalysis in the Philosophical Investigations, he mentions it only twice in the Big Typescript (303e, 433e) and three times in all the Collected Works (BB p.22, 57 and CV p. 42), even though, most of these remarks do not concern the analogy between philosophy and psychoanalysis. ${ }^{7}$

The analogy of philosophy with psychoanalysis, mentioned by Wittgenstein on the Big Typescript (303e) aims to emphasize that philosophy is not a matter of convincing by means of arguments but of persuading people to free themselves of false analogies that shape their conceptions. In this sense, proving that an analogy is misleading depends on the fact that people acknowledge it. "For only if he acknowledges it as such, is it the correct expression. (Psychoanalysis.) What the other person acknowledges is the analogy I'm presenting to him as the source of his thought." (WITTGENSTEIN, 2005, 303e)

Baker himself acknowledges that the comparison with psychoanalysis is an analogy and that is not developed very far. This is exactly because it has a scope/range. The analogy is not something to be compared in every term, but it is a technique to flag up some similarities or/and differences. As we can see in his own words: "The analogy with psychoanalysis is not developed very far or at all systematically (...), and this makes it impossible to establish exactly what Wittgenstein had in view in drawing it." (BAKER 2004, 145). I believe it is used to show the importance of the interlocutor's 
or reader's willingness to consider things in different ways.

Let us see another cases in which Wittgenstein refers to psychoanalysis:

A mathematician is bound to be horrified when faced with my mathematical remarks, since his schooling has always diverted him from giving himself over to thoughts and doubts of the kind that I am bringing up. He has learned to regard them as something contemptible and, to use an analogy from psychoanalysis (this paragraph is reminiscent of Freud), he has acquired a revulsion against these things as against something infantile. That is to say, I'm bringing up all of those problems that a child learning arithmetic, etc., finds difficult, the problems that classroom instruction suppresses without solving. So I'm saying to those suppressed doubts: You are quite right, go ahead and ask - and demand clarification! (WITTGENSTEIN, 2005, 433e)

On a first reading of this passage one understands that the analogy with psychoanalysis indicates that the mathematician represses his own enquiries about the nature of mathematics (geometry, arithmetic) because he was repressed several times when he was a child. Under this interpretation this remark obviously regards the supposed reasons why the mathematicians are usually not concerned with the philosophical questions of mathematics, that is, it does not regard the analogy with philosophy, i.e. although Wittgenstein mentions that he is using an analogy with psychoanalysis, this analogy is used to refer to the psychological reasons why the mathematician resists to face his enquiries.

On a second reading of the same passage one may consider that the analogy meant by Wittgenstein is indeed between psychoanalysis and philosophy and, therefore, it must be explained to account for my position which is contrary to Baker's view. In fact, if we understand that Wittgenstein brings up the questions about the foundations of mathematics, as much as psychoanalysis tries to unravel the unconscious reasons that make someone to do something or consider something on a certain way - to free the suppressed wishes and thoughts - we will acknowledge that this is precisely where the analogy with psychoanalysis and philosophy can be understood correctly: Philosophy wants to raise questions about the foundations of mathematics, for example, to clarify their nature.

In the blue book we can find another good example of how the analogy between philosophy and psychoanalysis works:

Consider this case:--we have a general undirected feeling of fear. Later on, we have an experience which makes us say, "Now I know what I was afraid of. I was afraid of so-and-so happening". Is it correct to describe my first feeling by an intransitive verb, or should I say that my fear had an object although I did not know that it had one? Both these forms of description can be used. To understand this examine the following example: It might be found practical to call a certain state of decay in a tooth, not accompanied by what we commonly call toothache, "unconscious toothache" and to use in such a case the expression that we have toothache, but don't know it. It is in just this sense that psychoanalysis talks of unconscious thoughts, acts of volition, etc. Now is it wrong in this sense to say that I have toothache but don't know it? There is nothing wrong about it, as it is just a new terminology and can at any time be retranslated into ordinary language. On the other hand it obviously makes use of the word "to know" in a new way. If you wish to examine how this expression is used it is helpful to ask yourself "what in this case is the process of getting to know like?" "What do we call 'getting to know' or, 'finding out'?" (WITTGENSTEIN, 1969, 22)

This passage synthesizes well one of the aspects that the analogy with psychoanalysis highlights: when we say that something is unconscious we refer to 
something that we don't know, that it doesn't occur to us, but that in a certain way has an influence. In this sense philosophy may be understood analogously to psychoanalysis given that both of them try to show unacknowledged influences of which we are not aware or we don't realize. As an example of clarification we can mention PI 104, when Wittgenstein points out the example of the water, quoting Faraday and stating that "One predicates of the thing what lies in the mode of representation. We take the possibility of comparison, which impresses us, as the perception of a highly general state of affairs." (WITTGENSTEIN, 2009 §104)

If we check the context in Faraday's text we can clearly see that the idea of purity is in the center of the idea of something unchangeable and essencial:

Here, in this bottle, is a quantity of water--perfectly pure, distilled water, produced from the combustion of a gas-lamp--in no point different from the water that you distil from the river, or ocean, or spring, but exactly the same thing. Water is one individual thing it never changes. We can add to it by careful adjustment, for a little while, or we can take it apart, and get other things from it; but water, as water, remains always the same, either in a solid, liquid, or fluid state. (FARADAY, 1908, 18)

And after that, in PI 107, Wittgenstein states that "For the crystalline purity of logic was, of course, not something I had discovered: it was a requirement." This is clearly an example of a case in which Wittgenstein acknowledges an important influence of his view about the purity of logic, namely, the analogical thought with water as a pure element. In this case we can evidently identify that the analogical thought was perhaps the unconscious reason why Wittgenstein was captured in the view of logic as pure and unchangeable.

It is worthy to observe Wittgenstein's acknowledgement of the influence of analogies as reference for Tractatus's statements. He also points to the fact that the simile only emphasizes two aspects. In the example of a sick person and the illness, he highlights the subjective and objective aspects.

One can - in a way others can understand - speak of combinations of colors with shapes (for example, of the colors red and blue with the shapes square and circle) just as one can speak of combinations of various shapes or bodies. And here we're at the root of my misleading claim that a fact is a complex of objects. So the fact that a person is ill is compared with a conjunction of two things, one of them the person, the other the illness. Let's not forget that that's only a simile. 177 (WITTGENSTEIN, 2005, 24e)

In the fourth example of the use of the word 'psychoanalysis', Wittgenstein, as we can see below, only clarifies that the discovery of the unconscious by psychoanalysis is a new mode of description. This means that this passage is not directly related to the analogy between philosophy and psychoanalysis and, for this reason, it is not relevant to my argumentation:

(...) Can we have unconscious thoughts, unconscious feelings, etc.?" The idea of there being unconscious thoughts has revolted many people. Others again have said that these were wrong in supposing that there could only be conscious thoughts, and that psychoanalysis had discovered unconscious ones. The objectors to unconscious thought did not see that they were not objecting to the newly discovered psychological reactions, but to the way in which they were described. The psychoanalysts on the other hand were misled by their own way of expression into thinking that they had done more than discover new psychological reactions; that they had, in a sense, discovered conscious thoughts which were unconscious. 
The first could have stated their objection by saying "We don't wish to use the phrase 'unconscious thoughts'; we wish to reserve the word 'thought' for what you call 'conscious thoughts'". They state their case wrongly when they say: "There can only be conscious thoughts and no unconscious ones". For if they don't wish to talk of "unconscious thought" they should not use the phrase "conscious thought", either. 176 (WITTGENSTEIN, 1969, 57)

The last quote of his use of 'psychoanalysis', Culture and Value, 42, does not present an analogy with philosophy. It is only a comparison about the contribution of Wittgenstein's work and the work on psychoanalysis:

My originality (if that is the right word) is, I believe, an originality that belongs to the soil, not the seed. (Perhaps I have no seed of my own.) Sow a seed in my soil, $\&$ it will grow differently than it would in any other soil. Freud's originality too was like this, I think. I have always believed--without knowing why--that the original seed of psychoanalysis was due to Breuer, not Freud. Of course Breuer's seed-grain can only have been quite tiny. (WITTGENSTEIN, 1998, 42)

\section{FINAL REMARKS}

After my main conceptual considerations and the evaluation of Wittgenstein's uses of 'psychoanalysis', it seems compulsory for me to say that Baker's attempt to include a subject to be treated is lacking justification. Of course philosophical problems are handled by subjects, but only to the extent that language is used by subjects/people. Wittgenstein never states nor mentions the subject as the aim of philosophy. On the contrary, his emphasis is always on language. "What we do is to bring words back from their metaphysical to their everyday use.” (WITTGENSTEIN, 2009, §116).

Why is it important to bring words back from their metaphysical to their everyday use? Because it makes us realize (comprehend/observe) the emptiness of the metaphysical use of words in language. Advancing the analogy with psychoanalysis doesn't mean that the method is supposed to treat someone's affliction. But it can flag the need to consider people's views or even a subject view. As the analogy with architecture emphasizes the way we see things. "As is frequently the case with work in architecture, work on philosophy is actually closer to working on oneself. On one's own understanding. On the way one sees things. (And on what one demands of them.)" (WITTGENSTEIN, 2005, 300e)

Besides that, even Baker acknowledges our tendency to consider philosophical problems as abstract problems, but he believes this tendency leads us to consider problems independently of subjects; but this is his misleading idea. "It is difficult to keep Waismann's conception sharply in focus: especially to resist the temptation to see 'our method' as a strategy for dealing with abstract problems which are to be investigated independently of any individual thinkers." (BAKER, 2004, 181]. We don't have to consider philosophical problems as abstract problems that exist by themselves independently of thinking-people/language-users. As we mentioned before, philosophical problems concern people to the extent that we are language users.

Naturally, we are not going to state that all Baker's inferences are unjustifiable, but we surely have to say that the analogy with psychoanalysis, in Wittgenstein's work, cannot go so far. To sum up, our motives are: First, the number of references to this analogy in Wittgenstein's writings is, as we mentioned before, very small. Second, extending the philosophical activity to concerns with a subject's affliction is a distortion 
of the role of philosophy by its approximation with psychoanalysis. There is no reason to consider extending the analogy as Baker proposes, given that it brings the problems we mentioned, namely, it fails to recognize a fundamental distinction between conceptual thinking and feeling, or, in other words, an important distinction in the grammar of 'thinking' and 'feeling'.

If Wittgenstein's philosophical method is somehow a therapy, it is not a therapy of the subject.

\section{Abbreviations:}

PI WITTGENSTEIN, L. 'Philosophical Investigations' Transl. G.E.M. Anscombe, P.M.S.Hacker and Joaquim Schulte. Wiley Blackwell, Oxford, 2009.

BB WITTGENSTEIN, L. 'The Blue And Brown Books'Blackwell Publishing, Oxford. 1969.

CV WITTGENSTEIN, L. 'Culture and Value' Edited by Georg Henrik von Wright, translated by Peter Winch, Blackwell Publishing, Oxford, 1998.

\section{REFERENCES}

BAKER G. P. Wittgenstein's Methods - neglected aspects Blackwell, Oxford - UK, 2004

BAKER G. P. Friedrich Waismann: A Vision of Philosophy - Philosophy, Vol. 78, No. 304, pp. 163-179 - Cambridge University Press, Abril 2003.

FARADAY, M. "The chemical history of a candle" - Ed. Chatto and Windus, London, 1908.

WAISMANN, F. How I See Philosophy. New York - St. Martin's Press, 1968.

WAISMANN, F., WITTGENSTEIN, L. e BAKER G. P. Dictations to Waismann from Wittgenstein: The Voices of Wittgenstein: Preliminaries to the Vienna Circle Project, London and New York: Routledge, 2003.

WITTGENSTEIN L. 'Philosophical Investigations' Trad. G.E.M. Anscombe, P. M. S. Hacker and Joaquim Schulte. Wiley Blackwell, Oxford - UK, 2009.

WITTGENSTEIN L. The collected works of Ludwig Wittgenstein, Oxford - UK, Ed. Blackwell Publishers, 1998.

WITTGENSTEIN L. 'The Blue And Brown Books' Blackwell Publishing, Oxford. 1969.

WITTGENSTEIN L. 'The Big Typescript' Edited and translated by C. Grant Luckhardt and Maximilian A. E. Aue. Blackwell Publishing, Oxford - UK, 2005.

\section{Notas}

1 “"our method' (G 26) i.e. the method learned from Wittgenstein, demonstrated in the writings of Waismann and Schlick." (BAKER, 2004, 145)

2 In note 3 Baker says: "Arguably it continued to dominate Wittgenstein's later work."

3 These four pillars are Baker's interpretations of Waismann's view.

4 “'(...) a 'philosophical problem' is not simply the cause or object of such torment or anxiety, the problem is the anxiety. Philosophical problems are philosophers' problems: "What we call "philosophical problems" are particular personal disquiets(...)" [Baker, 2004, p. 6 - Introduction of Katherine Morris]

5 In this paper I'm not delving into the question of where problems are, nor arguing for a positive view that they are in language, but merely suggesting that, if we have to pick between subject and language, we should not go with the subject, for the reasons I present here.

6 Naturally we are not defending that generating is the same as causing. But in this context, they share the same feature that is related to the notions of preceding and implying.

7 Shortly before we continue on the word psychoanalysis, it is worthy to note that 
Wittgenstein mentions 'therapies' only once in Philosophical Investigations (§133) and nowhere else. In this one and only case, mentioning 'therapies' is aiming to emphasize the statement that there is no singular way of philosophizing, but instead, there are several kinds of reasoning and presenting different kinds of analogies with different purposes (either pointing out similarities or differences, or drawing the limits of concepts), that can be considered under the name of 'Wittgenstein's philosophical methods'. "There is not a single philosophical method, though there are indeed methods, different therapies, as it were." (WITTGENSTEIN, 2009 §133) 